\title{
NEWS AND COMMENTS
}

The fourth and concluding number of the first volume of the Classical Quarterly contains inter alia papers on Aberdeen Papyri by Mr. Winstedt, on some excentricities in scansion in the Halieutica ascribed to Ovid by Mr. A. E. Housman, on the readings and kinship of the Madrid MS of Manilius by the same, on the 'idle actor' in Aeschylus by Mr. J. T. Allen, on the question whether the Heraclidae of Euripides is complete as we have it by Miss G. $\mathbf{H}$. Macurdy, a short but important note on a passage of Cicero's letters to Atticus by Mr. C. L. Smith, casting doubt on a visit of the writer to Antium, which has been generally assumed, a somewhat longer one by Mr. E. Harrison, upon the right place in British history of some events recorded by Tacitus, further emendations of treatises of Seneca by Mr. A. J. Kronenberg, a few etymologies by Mr. E. W. Fay, and some corrections of the results in Mr. H. D. Naylor's 'Doubtful Syllables in Iambic Senarii,' by Mr. H. W. Greene with an addendum by the author. There are six reviews including a very full one of $\mathrm{Mr}$. Cornford's Thucydides Mythistoricus by the editor. Other notices are Burnet's Plato (V) by Mr. R. G. Bury, Kenyon and Bell's British Museum Papyri and Jouguet's Lille Papyri by Mr. A. S. Hunt, Reitzenstein's recently published supplement to Photios' lexicon by Mr. T. C. Snow, and Schönfeld's Teutonic Proper Names in Greek and Latin by Mr.'H. M. Chadwick. A Complete index to Vol. $I$ is appended.

Attention should be called to an important paper issued by the Board of Education, the
Teaching of Classics in Prussian Secondary Schools, by J. L. Paton, Master of Manchester Grammar School (Vol. 20 of Special Reports). This gives by far the best account of the subject that we have seen, and is full of instruction for English schools.

A paper of instructions has also been issued by the Board on the Teaching of Latin in Secondary Schools. In this is a brief justification of Latin as a school subject in non-classical schools, and hints on method. A grounding in English is assumed as the basis, and it is laid down that two new languages should never be begun together; the importance of oral work is also insisted on.

We are glad to see that Dr. Olcott's valuable Thesaurus of Latin Inscriptions (see C.R. 1906, p. 178 ) is continuing its steady progress. Three parts bringing the work down to Aliger have been already published in the present year.

A CORRespondent suggests that it might: be useful to open a column in the Revieze for Questions and Answers, and we accordingly do so with a couple which he has sent us. Contributors are requested to send their names and addresses to the editor, but these need not be published.

The Annual Meeting of the Classical Association took place on Oct. I 8 and I9 at Cambridge. The Report of the CurriculaCommittee was adopted: we shall have occasion to speak of this Report later. It is understood that there is other work for this Committee to do. A Classical Association is being formed for Ireland specially.

\section{CORRESPONDENCE}

To Editor of The Classical Review.

Opinions will always differ as to what is vivacity and what is 'slangy colloquial mannerisms.' Your reviewer of my little book on Life in Ancient Athens singles out one specimen of the latter. The words 'gave a tremendous thump on the door with his stick' are apparently slangy and colloquial. It is an unfortunate thing that the late Prof. Jowett is not here to defend himself. The words happen to be his.

It is unfortunate also that a reviewer who objects 
to my 'transliteration' should write 'Lycaeum' for 'Lyceum,' and should furthermore interpolate his own spelling (a very curious one to occur to a ‘specialist') into a passage quoted from me.

T. G. TUCKER.

In the Classical Reviezy xxi. (1907) 155, writing about Miss Hamilton's book on Incubation, you make the following statement :

The second part, Incubation in Christian Churches, during the Middle Ages, breaks almost new ground. She has searched the Acta Sanctorum and records of saintly miracles, and has collected a considerable amount of illustration of the ancient practice.

I think a comparison of this chapter with Deubner, de incubatione cap. iv, will shew that the whole collection of illustration does not break new ground, but follows a given route. The system of quotation followed by Miss Hamilton does not make this clear. Nor would the reader of Miss Hamilton's Introduction pp. $4 \mathrm{ff}$. suspect that the identical disposition and illustrations (the latter more numerous) are to be found in Deubner's de incubatione, cap. i. pp. 10-13.

Pray do not think the motive of these remarks to be purely personal. Prof. Deubner's book appeared seven years ago, and has had time to take its proper place in Germany. Also Miss Hamilton's book addresses itself to a different audience.

O. C. Deubner, née LiNDLEY.

\section{MALARIA IN ANCIENT GREECE AND ITALY.}

The little book which has just appeared on the above subject is necessarily limited in scope, as its true object is to show how malaria affects character, and sometimes even influences the destiny of nations. But there are two other points which are, I think, of some importance, and worthy of attention at the hands of any who are interested in this question.

A modern physician, in diagnosing a case of malaria, relies upon his thermometer, his microscope, and the action of quinine. The ancient doctor used his eyes and his fingers; and accordingly, by continual practice, the faculties of sight and touch became so sensitive that symptoms were noticed which seem to have escaped modern observers. I think that a study of these symptoms might throw light upon some problems of tropical and sub-tropical disease, for a physician like Galen had the recorded experience of centuries to help him in forming his conclusions.

A large portion, perhaps some hundreds of pages, of the ancient medical writers describe fevers having symptoms suggestive, now of typhoid, now of malaria. Some of these may be Malta fever, many are without doubt remittent malaria, but most appear to be cases of typhoid in patients previously infected with the malaria parasite. Instances of this are by no means uncommon, and there results a curious combination o the two diseases, the typhoid assuming a malaria form.

I should like to state in conclusion that furthe study of the Hippocratic treatises, which of cours imply much experience previous to Hippocrates, con vinces me that the Greeks of the East were familia with malaria long before it became endemic in Attica Will anyone try to discover whether malaria influence the history of the Assyrians and Persians?

W. H. S. JONES.

Apropos of your timely editorial in the Classica Review for August, p. $\mathrm{J}^{8} 8$, on careless publishers o old emendations, be it noted that editors are as likel. to offend in this respect as their contributors. Fo example, in Mnemosyne, vol. xxxiv. (1906) p. 306 Van Leeuwen proposed to read 'in i m b r em' fo 'in hominem' in Terence's Eunuchus, 1. 588 although that conjecture had already been proposer by $\mathrm{M}$. Fabia and introduced into the text in hi edition of the Eunuchus, Paris, I895.

\section{ROY C. Flickinger.}

\section{QUESTIONS AND ANSwers.}

r. What is the meaning of the passage ir Pliny, N.H. 37. $5(64)$ 'Nero princeps gla diatorum pugnas spectabat in zmaragdo. Did Nero use the emerald as a mirror or a: a magnifying glass ?

2. Is there any principle by which one ma! be guided as to the force of the prepositior in compound verbs in the Kocv'? It is recognised, I believe, that the writers of tha period, in their consciousness of the weakenin of language that is always going on, resortec to the use of compound for simple verbs with the idea of adding strength to their expression But is there any safe rule to guide one as $t$ when the preposition has its force? Or is i only a question of context and commor sense? For example: in St. Mark xiv. 4! the Revised Version in the margin give

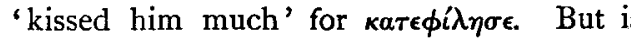
this in any way justified? Is not the com pound verb here simply an equivalent of th simple? The question may often be one o considerable importance in New Testamen exegesis.

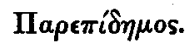

